\title{
CFD SIMULATION ON DIFFERENT GEOMETRIES OF VENTURIMETER
}

\author{
P. Hari Vijay ${ }^{1}$, V. Subrahmanyam ${ }^{2}$ \\ ${ }^{I}$ M.Tech Scholar, Department of Mechanical Engineering, Kakinada Institute of Technology and Science, Divili, \\ Andhra Pradesh, India \\ ${ }^{2}$ Associate Professor, Department of Mechanical Engineering, Kakinada Institute of Technology and Science, Divili, \\ Andhra Pradesh, India
}

\begin{abstract}
This paper describe an analytical approach for comparison of four different models to describe the velocity, pressure, turbulence and mass flow rate taken place in the venturimeter and graph are plotted. Venturimeter are most commonly used for flow meters for measuring volumetric or mass flow rate and velocity of fluid flowing through the venturimeter. Hence are also know as variable head meters. Variable head meters work on the principle that a variation of the flow rate through a constriction with a constant cross-sectional area causes a pressure drop suffered by the fluid as it flows through the constriction. The pressure drop is related to the flow rate, and hence variations of the pressure drop can be used to measure variations in the flow rate. Fluent soft ware was used to plot the characteristics of the flow of fluid through the flow meter and gambit software was used to design the $2 D$ model. Two phase computational fluid dynamic calculation, using K-Epsilon model were employed. The numerical results were validated against experimental data from the literature and were found to be in good agreement. The pressure recovery is better in the venturi meter.
\end{abstract}

Keywords: Gambit, Fluent, K-Epsilon model..

\section{INTRODUCTION}

In different applications like chemical, paper and minerals processing industries these flow meters are used and also in order to control these processes and to calculate mass balances for these processes it is important to be able to accurately measure the flow rate of these fluids as they move through pipes, conduits, or channels. Variable head meters work on the principle that a variation of the flow rate through a constriction with a constant cross-sectional area causes a pressure drop suffered by the fluid as it flows through the constriction. The pressure drop is related to the flow rate, and hence variations of the pressure drop can be used to measure variations in the flow rate.

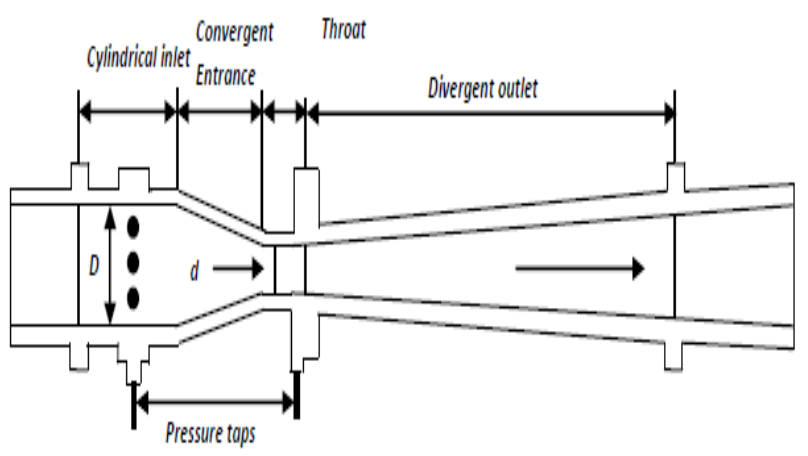

Fig-1.1: Venturimeter

A sketch of a typical venturimeter is shown in Fig 1.1.
The behavior of the fluid as it passes through the venturi is understood by writing the Bernoulli equation using the conditions at the entrance and the throat, and at the throat and the exit. As the fluid passes from the entrance to the throat, its velocity increases and its pressure decrease. Upon passing from the throat to the exit, the velocity of the fluid decreases and its pressure increases, largely recovering to its value at the entrance. The venturimeter is designed to recover most of the pressure drop.

\section{PROCEDURE AND GEOMETRY}

The current study used FLUENT software, to solve the balance equation using control volume approach. These equations are solved by converting the complex partial differential equations into simple algebraic equations. The simple geometry is done in the GAMBIT software, a fine meshing is done by using successive ratio and later given the boundary conditions for the geometry and for the media. This file imported into Fluent software and has given the input values like velocity, mass flow rate, pressure, temperature etc.,

The geometry was done in the GAMBIT with measurements; pipe diameter is $30 \mathrm{~mm}$, radius of the pipe $15 \mathrm{~mm}$ and length of the pipe $200 \mathrm{~mm}$. Defining required boundaries like inlet, outlet and wall of the geometry and mesh under tetrahedron. Defining the boundary conditions for the water. The velocity at inlet is $4 \mathrm{~m} / \mathrm{sec}$ and the gravitational acceleration of $9.81 \mathrm{~m} / \mathrm{s} 2$ in downward flow direction was used. 


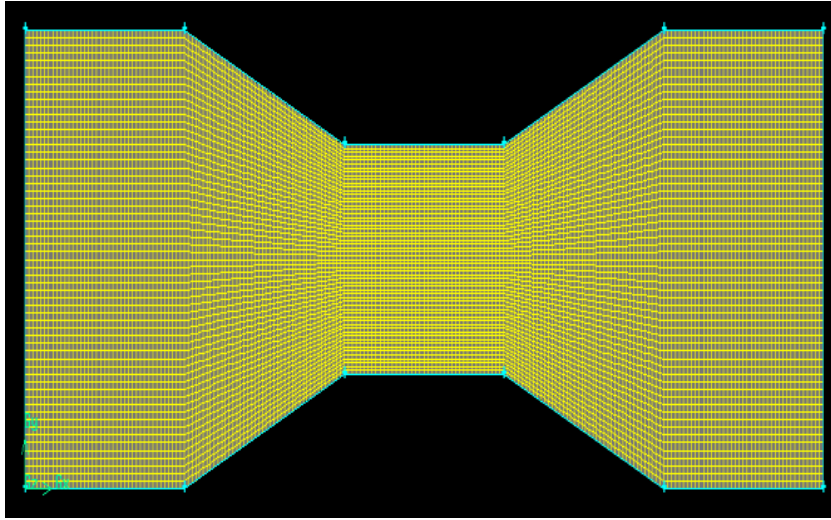

Fig-2.1: First model venturimeter.

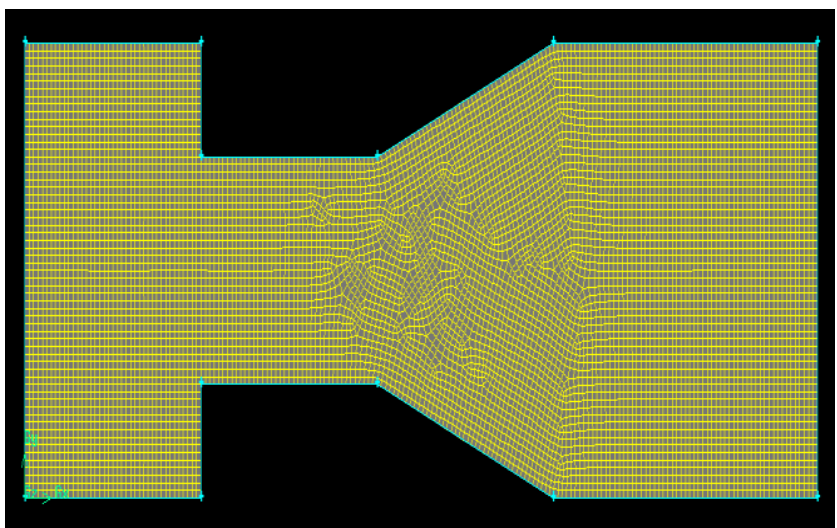

Fig-2.2: Second model venturimeter.

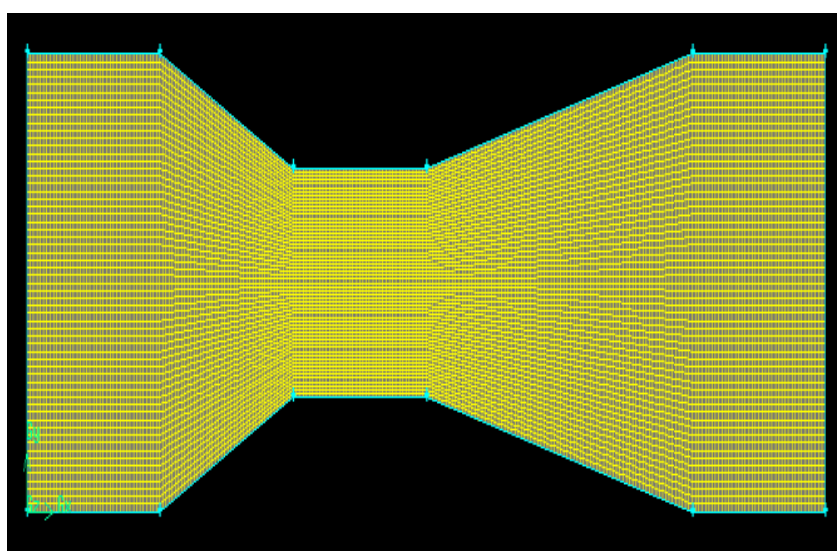

Fig-2.3: Third model venturimeter.

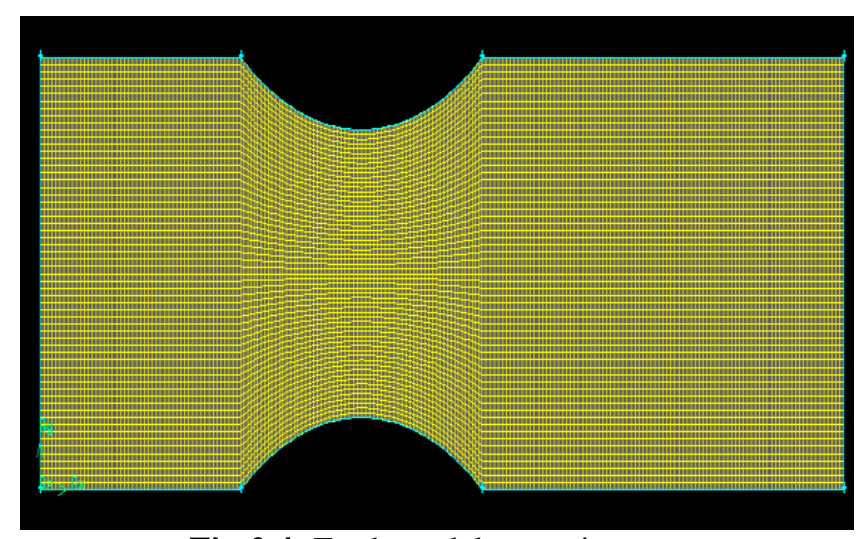

Fig-2.4: Forth model venturimeter.

\section{SOLUTION STRATEGY}

The simulation is done in the FLUENT based upon the governing equations. The steps followed in the fluent are define Model, define Material, define cell zone, boundary condition, solve, iterate, and analyze results. The convergent of the solution is shown in below fig 3.1.

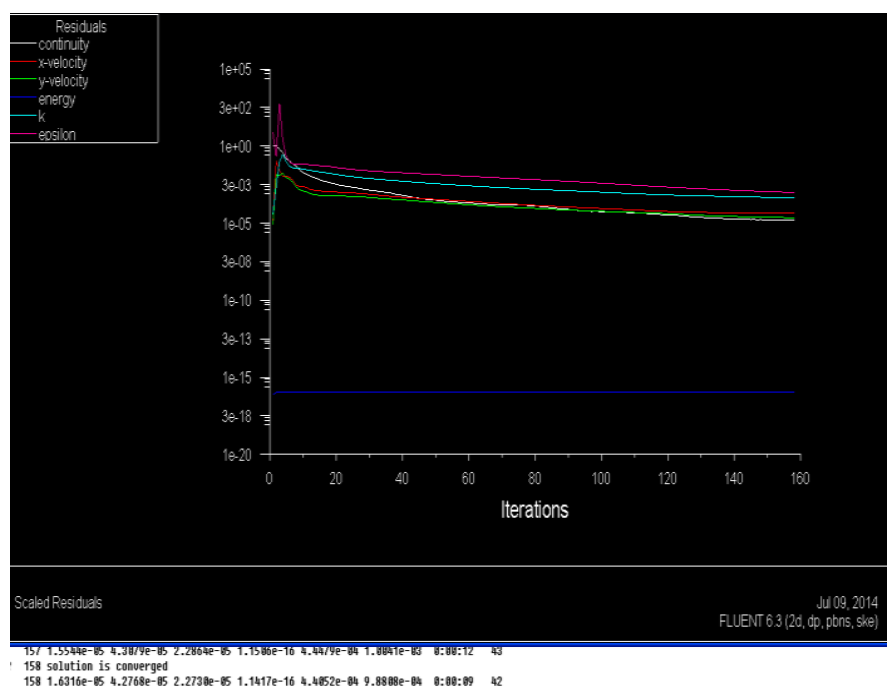

Fig-3.1: Iterations of solution.

\subsection{Continuity Equation.}

Continuity Equation also called conservation of mass. The overall mass balance is

$$
\text { Input }- \text { output }=\text { accumulation }
$$

Assuming that there is no storage the Mass input = mass output.

However, as long as the flow is steady (time-invariant), within this tube, since, mass cannot be created or destroyed then the above equation will be

$$
\begin{aligned}
& \mathrm{m}_{1}=\mathrm{m}_{1} \\
& \frac{\mathrm{dm}_{1}}{\mathrm{dt}}=\frac{\mathrm{dm}_{1}}{\mathrm{dt}} \\
& \rho \mathrm{A}_{1} \mathrm{u}_{1}=\rho \mathrm{A}_{2} \mathrm{u}_{2} \\
& \mathrm{~A}_{1} \mathrm{v}_{1}=\mathrm{A}_{2} \mathrm{v}_{2}
\end{aligned}
$$

\subsection{Momentum Equation and Bernoulli Equation.}

It is also called equation of motion .According to Newton's 2nd law (the time rate of change of momentum of the fluid particles within this stream tube slice must equal to the forces acting on it).

$$
\mathrm{F}=\text { mass } * \text { acceleration }
$$


Consider a small element of the flowing fluid as shown below, Let

dA : cross-sectional area of the fluid element,

dL : Length of the fluid element,

dW : Weight of the fluid element,

$\mathrm{u} \quad$ : Velocity of the fluid element,

$\mathrm{P} \quad$ : Pressure of the fluid element.

Assuming that the fluid is steady, non-viscous (the frictional losses are zero) and incompressible (the density of fluid is constant).

The forces on the cylindrical fluid element are,

Pressure force acting on the direction of flow (PdA).

Pressure force acting on the opposite direction of flow $[(\mathrm{P}+\mathrm{dP}) \mathrm{dA}]$.

A component of gravity force acting on the opposite direction of flow $(\mathrm{dW} \sin \theta)$.

Hence, Total force $=$ gravity force + pressure force

The pressure force in the direction of low

$$
F p=P d A-(P+d P) d A=-d P d A
$$

The gravity force in the direction of flow

$\mathrm{Fg}=-\mathrm{dW} \sin \theta\{\mathrm{W}=\mathrm{m} \mathrm{g}=\rho \mathrm{dAdL} \mathrm{g}\}$.

$=-\rho \mathrm{gdAdL} \sin \theta\{\sin \theta=\mathrm{dz} / \mathrm{dL}\}$.

$=-\rho \mathrm{g} \mathrm{dAdz}$.

The net force in the direction of flow

$\mathrm{F}=\mathrm{m}$ a $\{\mathrm{m}=\rho \mathrm{dAdL}$.

$=\rho \mathrm{dAdL}$.

$=\rho \mathrm{dA} \mathrm{u} \mathrm{du}$.

We have

$\rho \mathrm{dA} \mathrm{u} \mathrm{du}=-\mathrm{dP}$ dA $-\rho \mathrm{g} \mathrm{dA} \mathrm{dz}\{\div \rho \mathrm{dA}\}$

$\mathrm{dP} / \rho+\mathrm{udu}+\mathrm{dz} \mathrm{g}=0$--------- Euler's equation of motion.

Bernoulli's equation could be obtain by integration the Euler's equation.

$\int \mathrm{dP} / \rho+\int \mathrm{udu}+\int \mathrm{dz} \mathrm{g}=$ constant.

$\mathrm{P} / \rho+\mathrm{u} 2 / 2+\mathrm{zg}=$ constant

$\Delta \mathrm{P} / \rho+\Delta \mathrm{u} 2 / 2+\Delta \mathrm{z} g=0$-- Bernoulli's equation.

\section{RESULTS.}

\subsection{Results of First Model.}

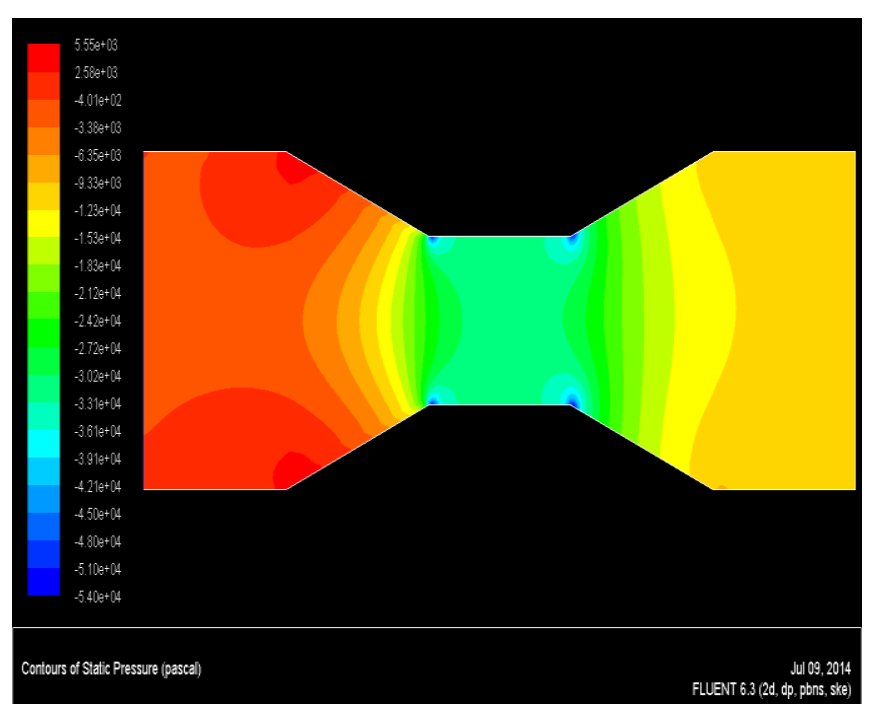

Fig-4.1.1: Pressure contours.

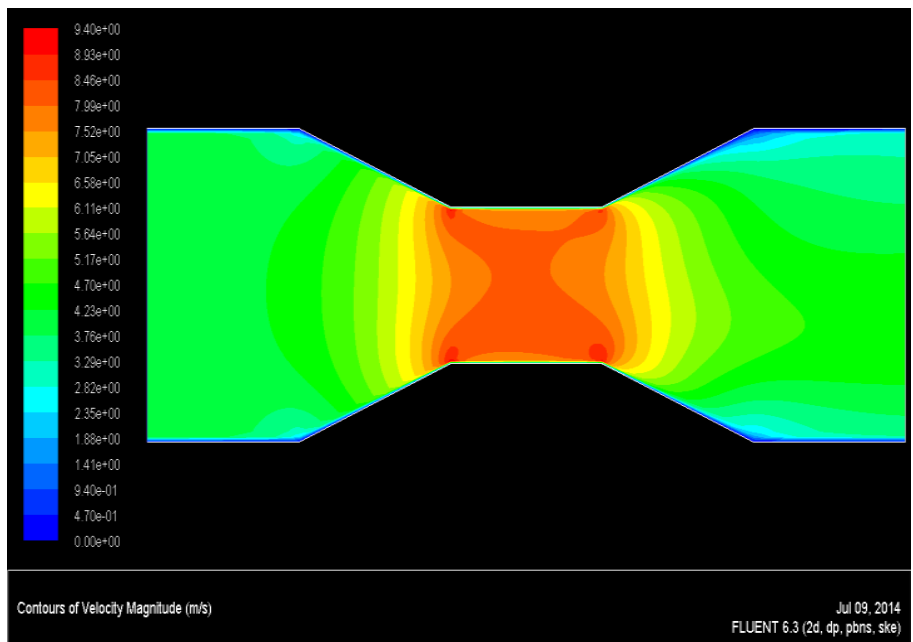

Fig-4.1.2: Velocity contours.

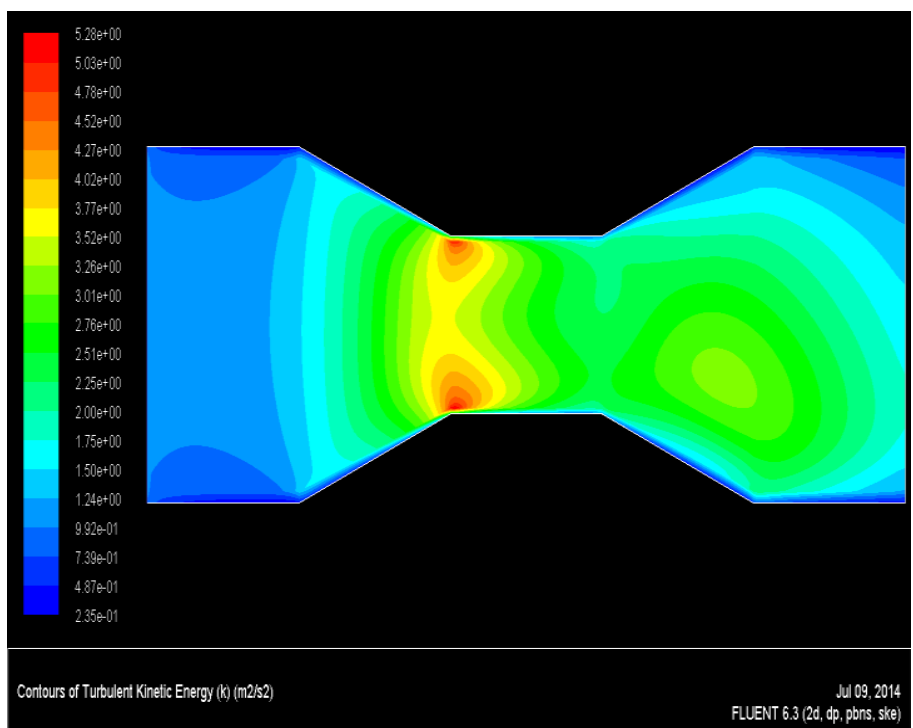

Fig-4.1.3: Turbulence contours. 


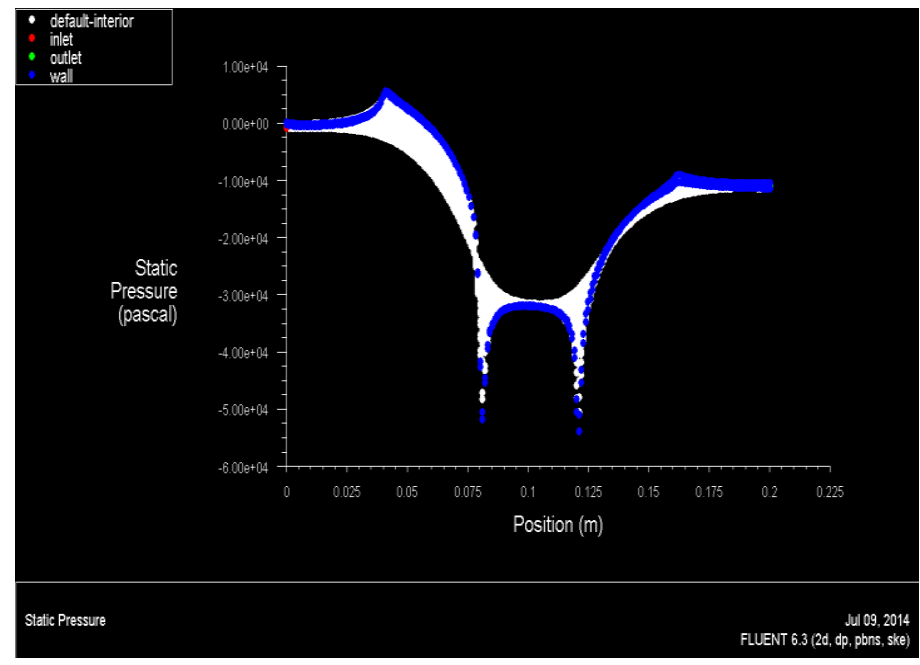

Chart-4.1.1: Static Pressure-Position.

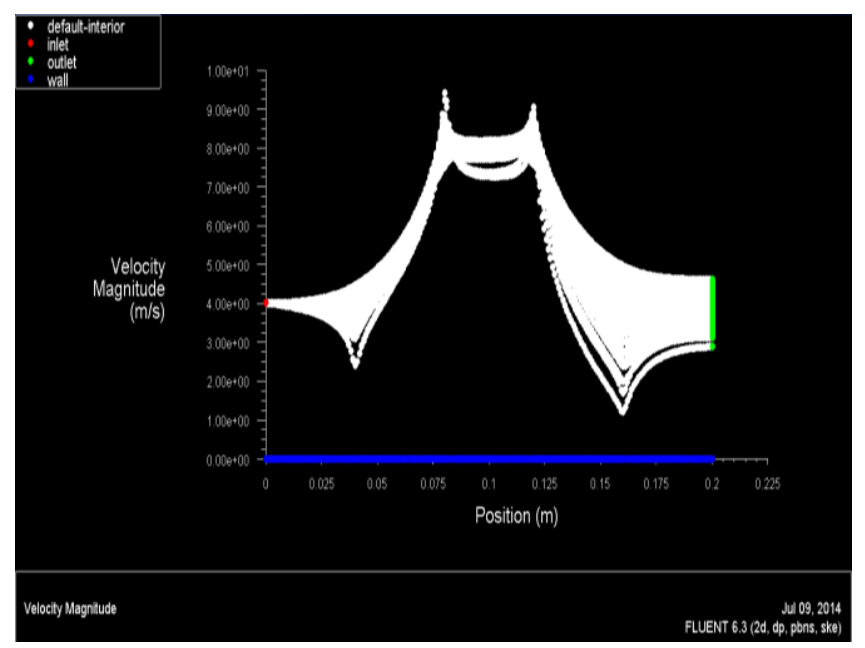

Chart-4.1.2: Velocity-Position.

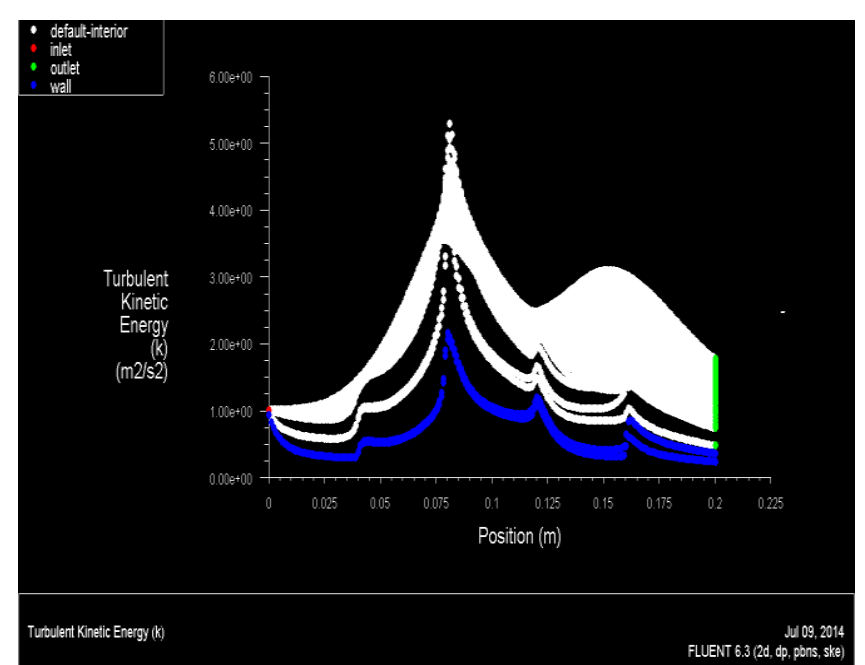

Chart-4.1.3: Turbulent-Position.

Table-4.1.1: Results of flow analysis.

\begin{tabular}{|l|l|l|l|}
\hline s.no & parameters & Min. & Max. \\
\hline 1 & Pressure $($ Pascal $)$ & -53977.21 & 5552.164 \\
\hline 2 & Velocity $(\mathrm{m} / \mathrm{s})$ & 0 & 9.4006 \\
\hline 3 & Turbulent $\left(\mathrm{m}^{2} / \mathrm{s}^{2}\right)$ & 0.2347 & 5.28177 \\
\hline
\end{tabular}

Table-4.1.2: Results of mass flow rate.

\begin{tabular}{|l|l|}
\hline Mass Flow Rate & $\mathbf{( k g / s )}$ \\
\hline Interior & -48874.855 \\
\hline Inlet & 239.56801 \\
\hline Outlet & -239.56801 \\
\hline Wall & 0 \\
\hline
\end{tabular}

\subsection{Results of Second Model.}

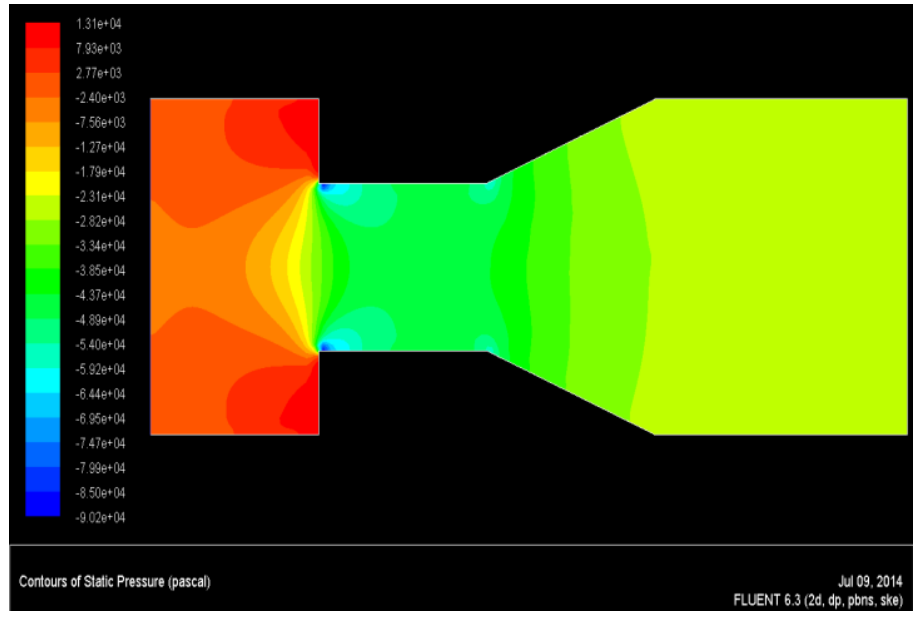

Fig-4.2.1: Pressure contours.

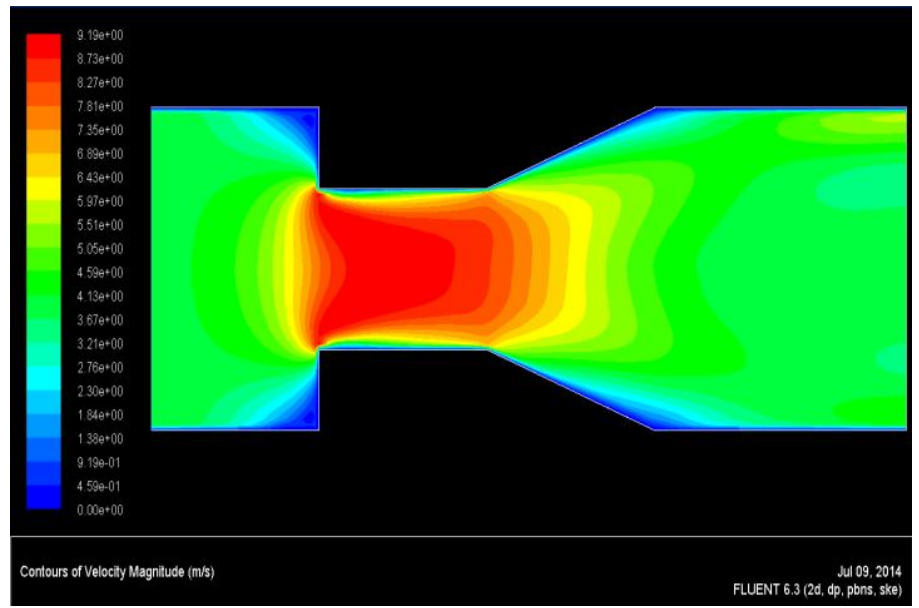

Fig-4.2.2: Velocity contours.

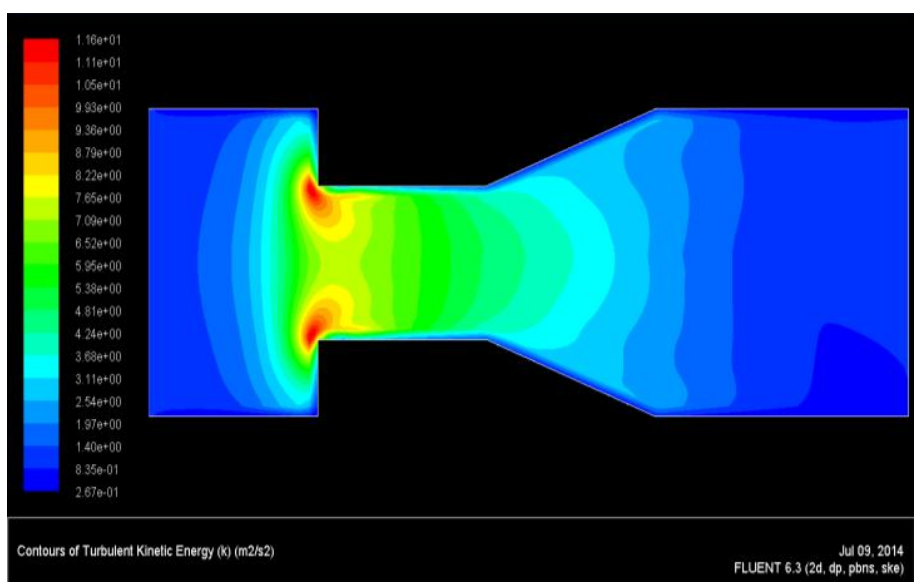

Fig-4.2.3: Turbulence contours. 


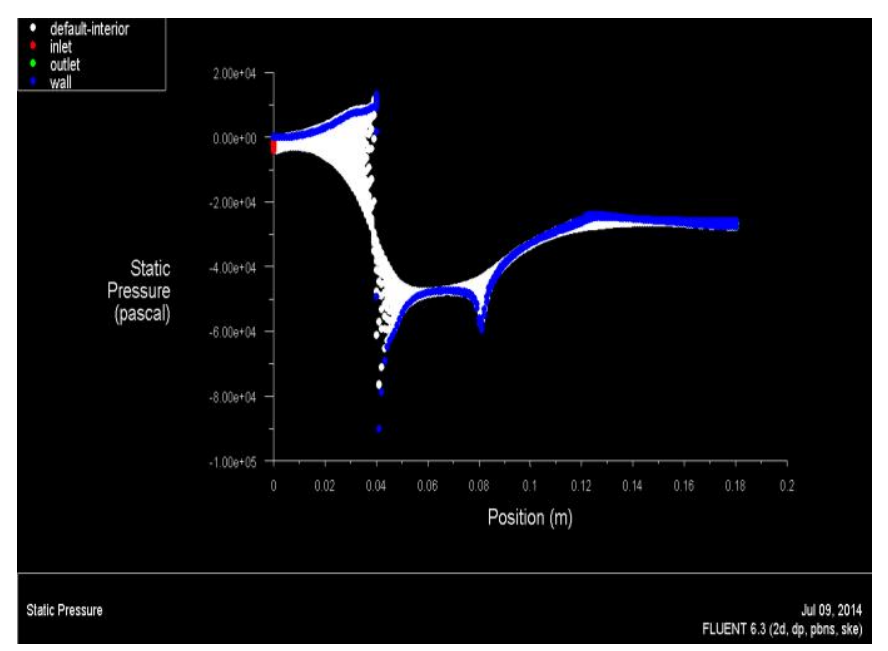

Chart-4.2.1: Static Pressure-Position.

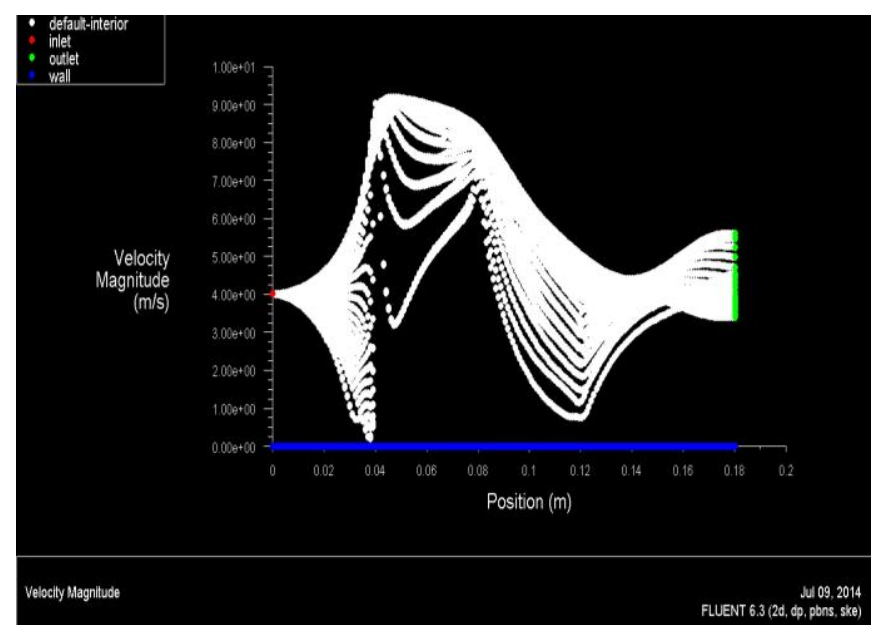

Chart-4.2.2: Velocity-Position.

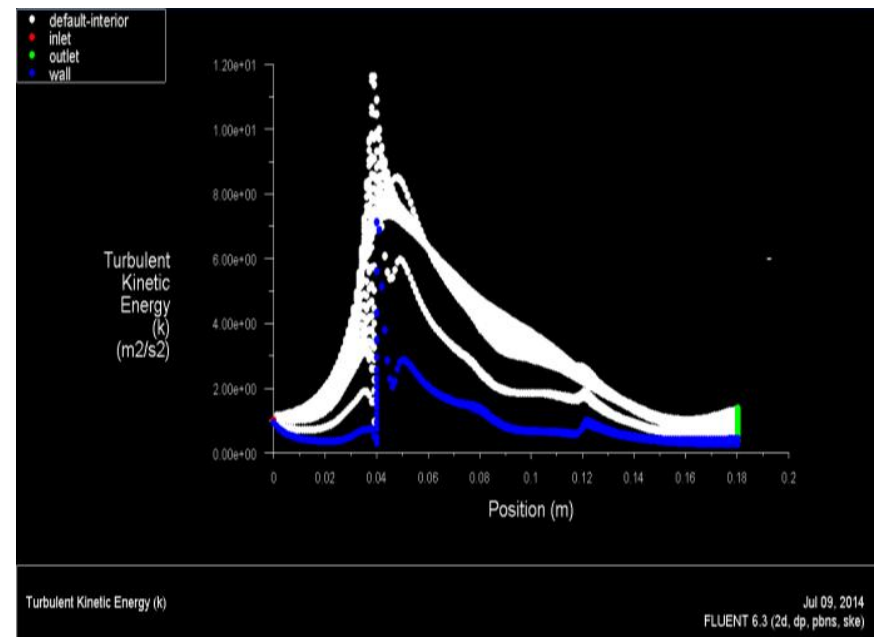

Chart-4.2.3: Turbulent-Position.

Table-4.2.1: Results of flow analysis.

\begin{tabular}{|c|c|c|c|}
\hline s.no & parameters & Min. & Max. \\
\hline 1 & Pressure $($ Pascal $)$ & -90194.45 & 13095.87 \\
\hline 2 & Velocity $(\mathrm{m} / \mathrm{s})$ & 0 & 9.185 \\
\hline 3 & Turbulent $(\mathrm{m} 2 / \mathrm{s} 2)$ & 0.2672125 & 11.630932 \\
\hline
\end{tabular}

Table-4.2.2: Results of mass flow rate.

\begin{tabular}{|c|c|}
\hline Mass Flow Rate & $(\mathrm{kg} / \mathrm{s})$ \\
\hline Interior & 1027.7252 \\
\hline Inlet & 239.56801 \\
\hline Outlet & -239.56801 \\
\hline Wall & 0 \\
\hline
\end{tabular}

\subsection{Results of Third Model.}

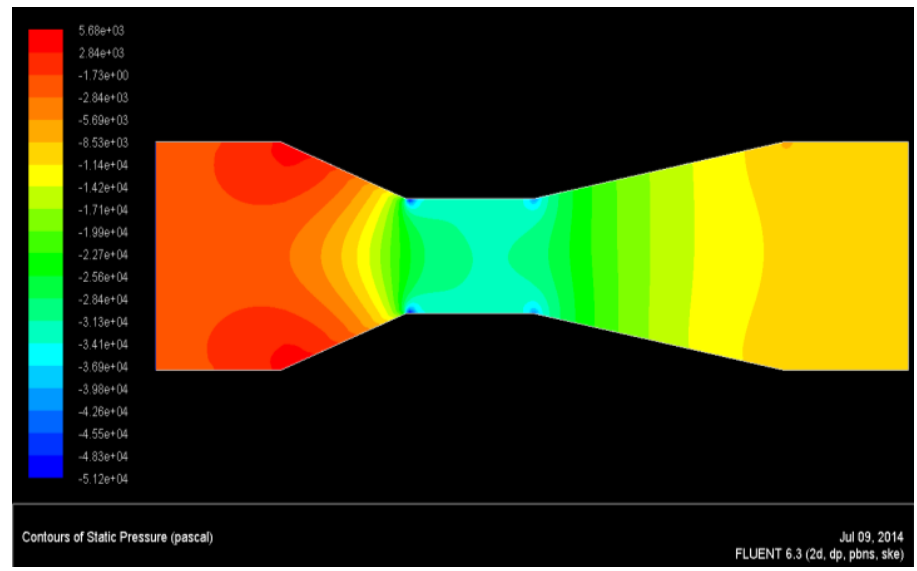

Fig-4.3.1: Pressure contours.

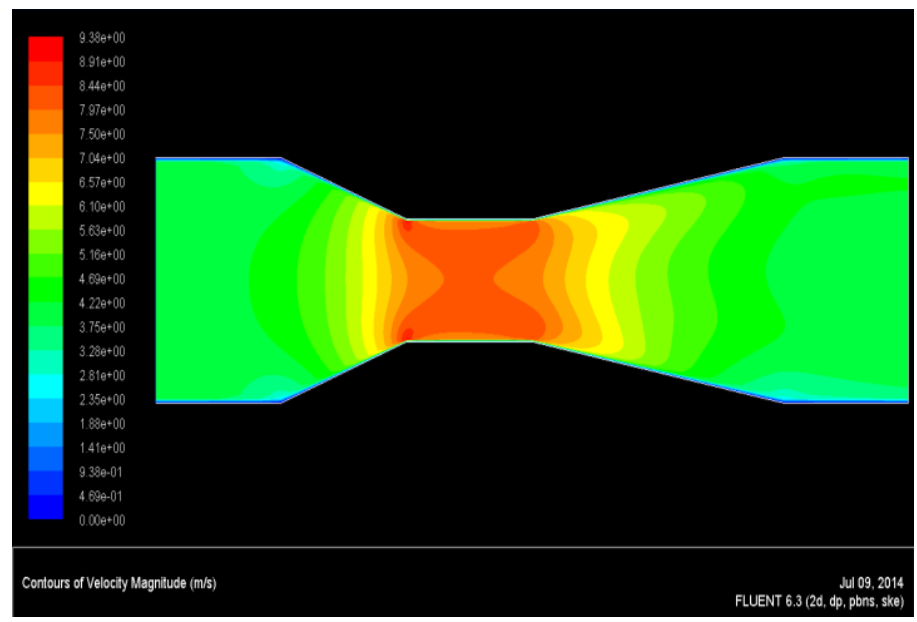

Fig-4.3.2: Velocity contours.

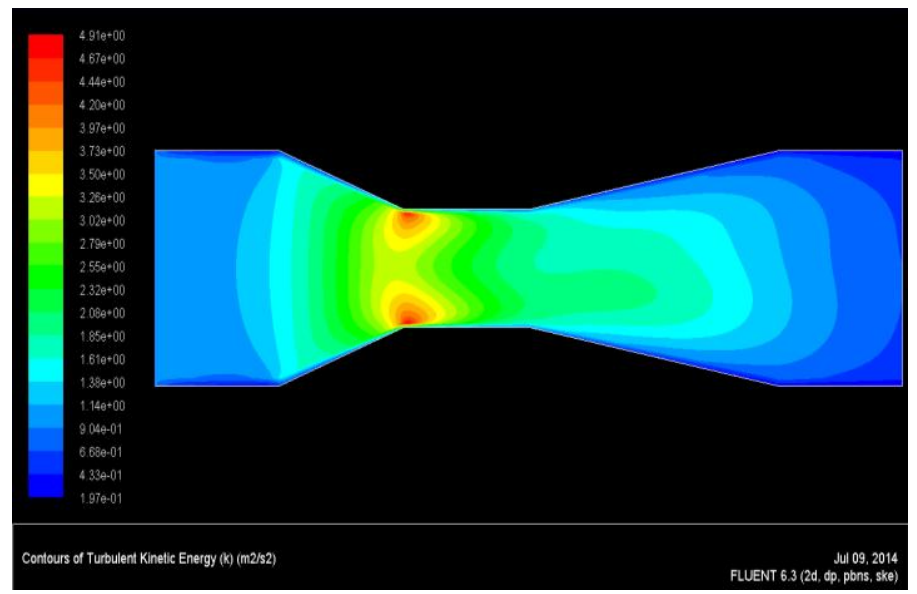

Fig-4.3.3: Turbulence contours 


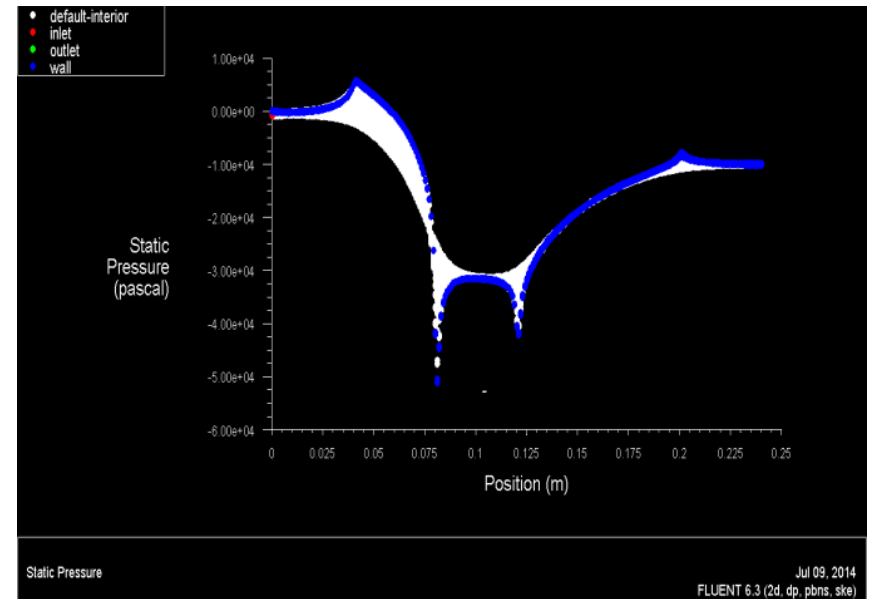

Chart-4.3.1: Static Pressure-Position.

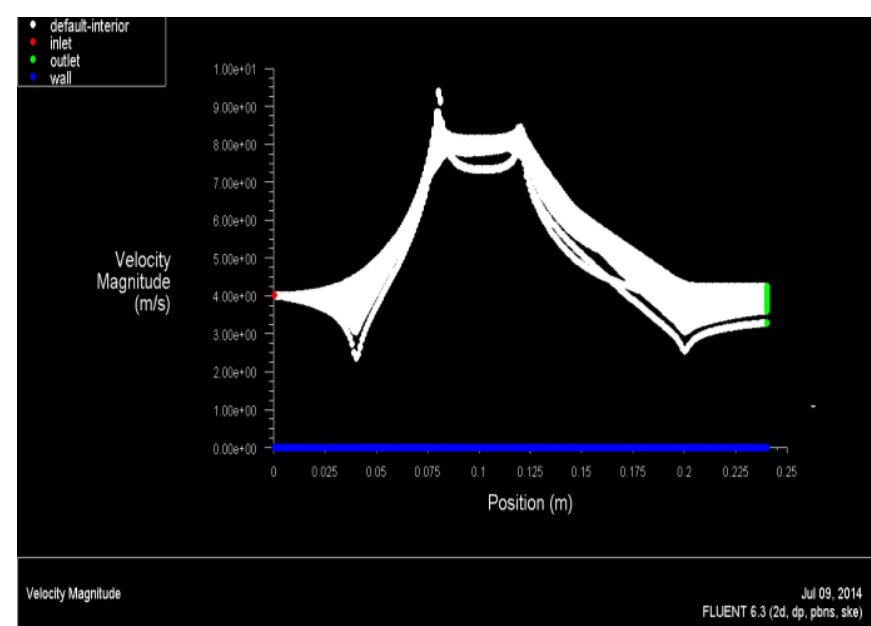

Chart-4.3.2: Velocity-Position.

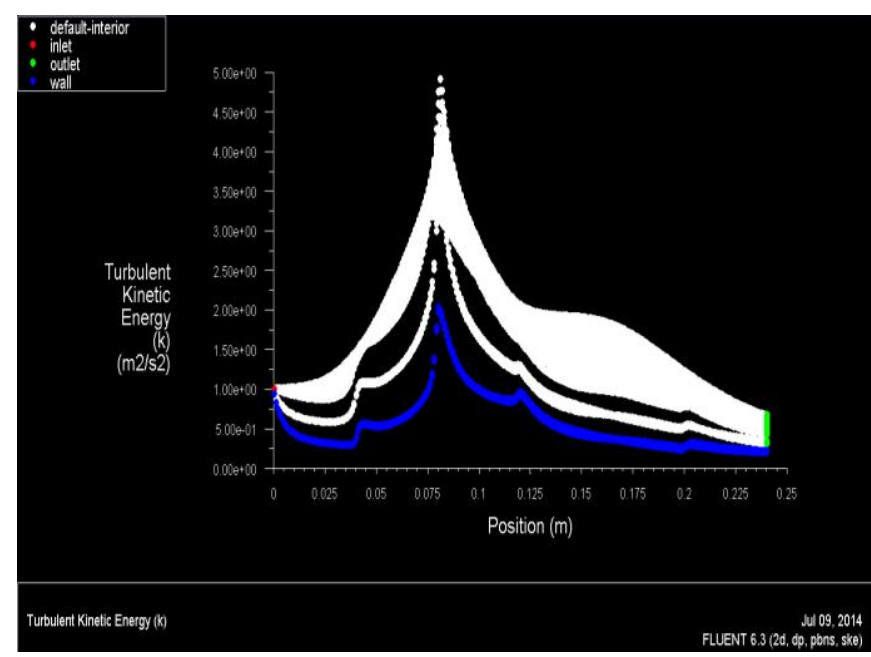

Chart-4.3.3: Turbulent-Position

Table-4.3.1: Results of flow analysis.

\begin{tabular}{|c|c|c|c|}
\hline s.no & parameters & Min. & Max. \\
\hline 1 & Pressure(Pascal) & -51152.82 & 5681.665 \\
\hline 2 & Velocity $(\mathrm{m} / \mathrm{s})$ & 0 & 9.38077 \\
\hline 3 & Turbulent $(\mathrm{m} 2 / \mathrm{s} 2)$ & 0.1972782 & 4.908975 \\
\hline
\end{tabular}

Table-4.3.2: Results of mass flow rate.

\begin{tabular}{|c|c|}
\hline Mass Flow Rate & $(\mathrm{kg} / \mathrm{s})$ \\
\hline Interior & -58327.486 \\
\hline Inlet & 239.56801 \\
\hline Outlet & -239.56801 \\
\hline Wall & 0 \\
\hline
\end{tabular}

\subsection{Results of Forth Model.}

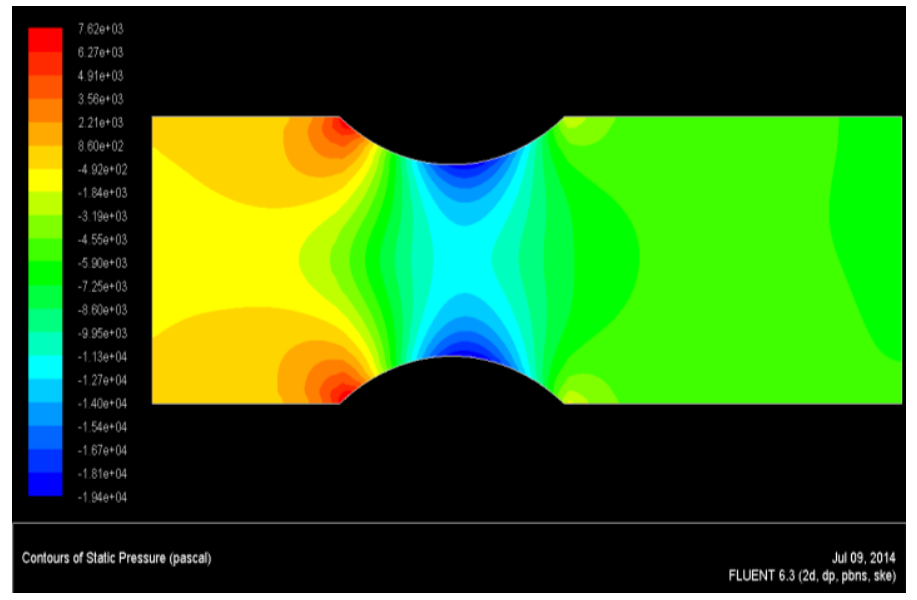

Fig-4.4.1: Pressure contours.

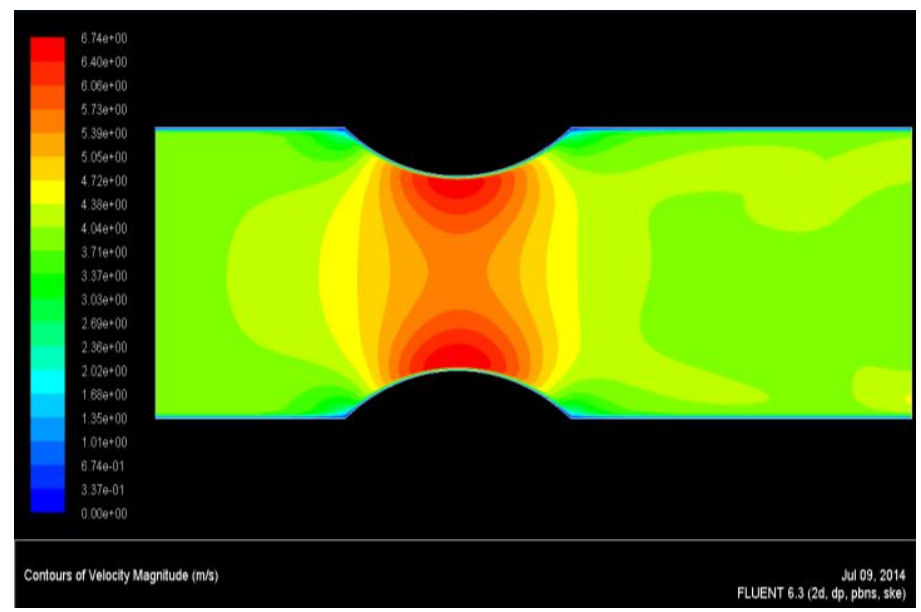

Fig-4.4.2: Velocity contours.

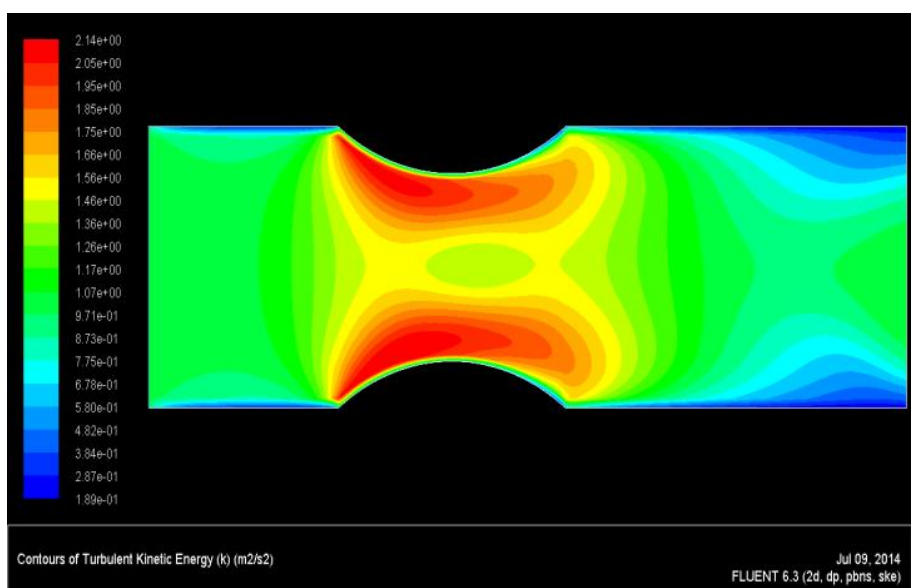

Fig-4.4.3: Turbulence contours. 


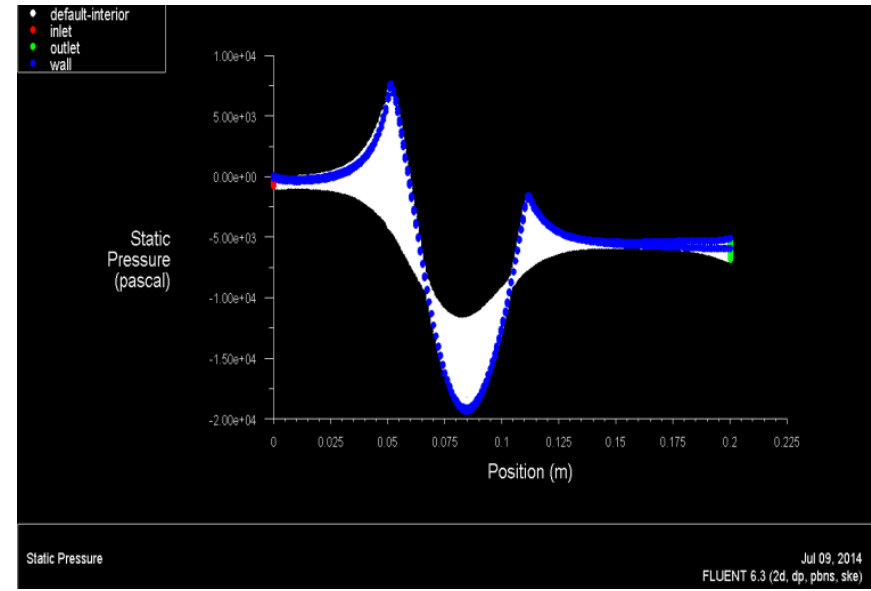

Chart-4.4.1: Static Pressure-Position.

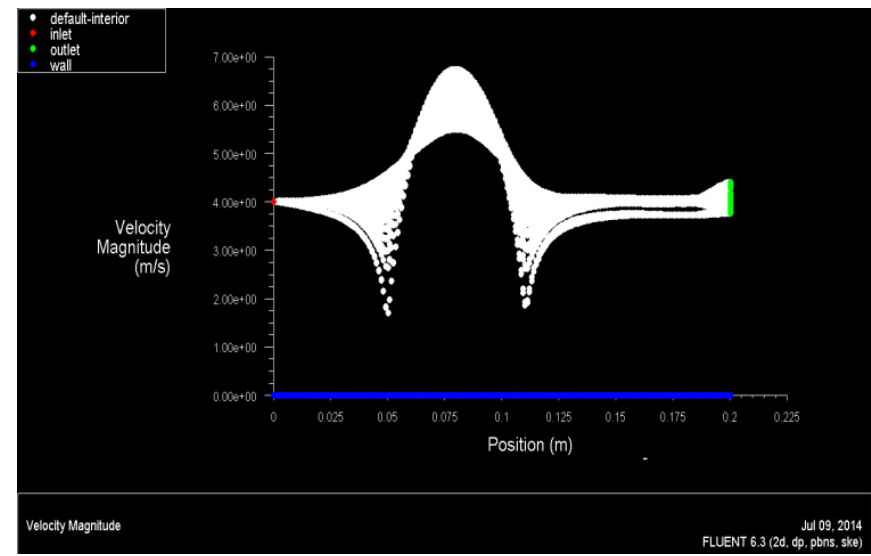

Chart-4.4.2: Velocity-Position.

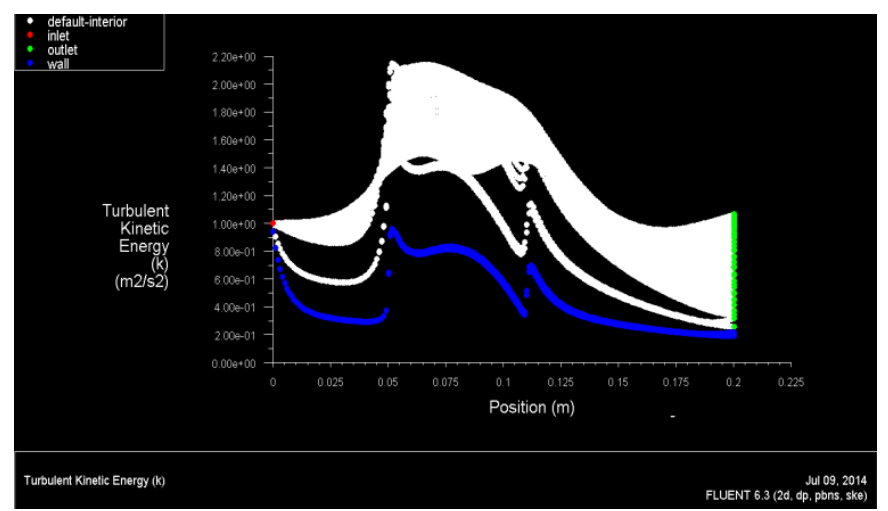

Chart-4.4.3: Turbulent-Position.

Table-4.4.1: Results of flow analysis.

\begin{tabular}{|c|c|c|c|}
\hline s.no & parameters & Min. & Max. \\
\hline 1 & Pressure $($ Pascal $)$ & -19414.05 & 7617.83 \\
\hline 2 & Velocity $(\mathrm{m} / \mathrm{s})$ & 0 & 6.73726 \\
\hline 3 & Turbulent $(\mathrm{m} 2 / \mathrm{s} 2)$ & 0.1887413 & 2.143962 \\
\hline
\end{tabular}

Table-4.4.2: Results of mass flow rate.

\begin{tabular}{|c|c|}
\hline Mass Flow Rate & $(\mathrm{kg} / \mathrm{s})$ \\
\hline Interior & -48615.779 \\
\hline Inlet & 239.56801 \\
\hline Outlet & -239.56801 \\
\hline Wall & 0 \\
\hline
\end{tabular}

\section{CONCLUSIONS}

The flow through venturi meter was numerically simulated with water by steady flow in k-epsilon scheme. The major observations made related to the pressure, turbulence, velocity contours and mass flow rate in the process of flow. The accuracy of results is with in 5\%. The velocity and pressure distribusions are discribed brifly and graphs are plotted.

To conclude, this examination results indicate that FLUENT can be used with high degree of accuracy to visualize the various contours of velocity, pressure and turbulence can be understand clearly, the relationship between the mass flow rate and pressure drop for each flow meter is done and pressure recovery is better in the venturimeter.

\section{REFERENCES}

[1]. Anderson, J. D. (1995). Computational fluid dynamics: The basics with applications (6th Ed.). New York, NY: Mcgraw Hill, Inc.

[2]. Versteeg, H.K. \& Malalasekera, W. (2007). An Introduction to Computational fluid dynamics: The Finite Volume Method (2nd Ed), New Jersey: Pearson education ltd

[3]. Cengel, Y. A. \& Cimbala J. M. (2010). Fluid Mechanics: Fundamentals and applications (2nd Ed), Noida, UP, India: Tata McGraw-Hill Education.

[4]. Sapra, M.K., Bajaj, M., Kundu, S.N., Sharma, B.S.V.G. (2011). Experimental and CFD investigation of $100 \mathrm{~mm}$ size cone flow elements.Flow Measurement and Instrumentation, 22, 469-474.

[5]. Singh, R.K., Singh, S.N., Seshadri, V. (2009). Study on the effect of vertex angle and upstream swirl on the performance characteristics of cone flowmeter using CFD. Flow Measurement and Instrumentation, 20, 69-74.

[6]. Hojat Ghassemi, Hamidreza Farshi Fasih (2011). Application of small size cavitating venturi as flow controller and flow meter. Flow Measurement and Instrumentation, 22, 406-412.

[7]. Denghui He, Bofeng Bai (2012). Numerical investigation of wet gas flow in Venturi meter. Flow Measurement and Instrumentation, 28, 1-6.

[8]. Singh, Rajesh Kumar, Singh, S.N., Seshadri V. (2010). CFD prediction of the effects of the upstream elbow fittings on the performance of cone flowmeters. Flow Measurement and Instrumentation, 21, 88-97.

[9]. Reader-Harris, M.J., Brunton, W.C., Gibson, J.J., Hodges, D., Nicholson, I.G. (2001). Discharge coefficients of Venturi tubes with standard and non-standard convergent angles. Flow Measurement and Instrumentation, 12, 135145.

[10]. Hall, G.W. Application of Boundary Layer Theory to Explain some Nozzle and Venturi Peculiarities Trans. IME, London Vol. 173 No.36 1959. 


\section{BIOGRAPHIES:}

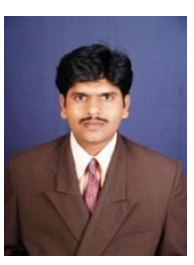

P.Hari Vijay completed schooling from Geetanjali public school, East Godavari district with $68 \%$ marks. Completed B.Tech degree from Aarupadai veedu institute of technology with $60 \%$. Now pursuing M.Tech from Kakinada Institute of Technology and Science, Tirupathi(V), Divili, East Godavari Dist., A.P., India.

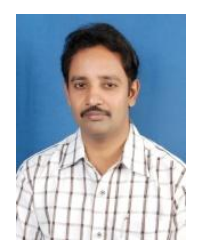

Mr. V.Subrahmanyam working as Assoc. Professor and Head of Mechanical Engineering Department in KITS-Divili Engineering college, Andhra Pradesh, India. $\mathrm{He}$ has 15 years of teaching experience in various reputed engineering colleges. He guided so many B.Tech and M.Tech projects. He has three publications in reputed international journals. He is doing research in Nano-Technology and Thermal Engineering 